\title{
Clinical Evaluation of Five Commercial Serological SARS-CoV-2 Immunoassays for COVID-19
}

\author{
Wooyong Shin ${ }^{\circledR}$, Hae In Bang ${ }^{\circledR}$, Geun Young Yu ${ }^{\circledR}$, Mi-Young Kim ${ }^{\circledR}$, Eui Young Jang ${ }^{\circledR}$, Jung-Ah Kim ${ }^{\circledR}$, \\ Jieun Kim ${ }^{\oplus}$, Rojin Park ${ }^{\oplus}$, Jeong Won Shin ${ }^{\circledR}$, and Tae Youn Choi ${ }^{\circledR}$ \\ Department of Laboratory Medicine, Soonchunhyang University Seoul Hospital, Seoul, Korea
}

\section{Corresponding author:}

Hae In Bang

Department of Laboratory Medicine, Soonchunhyang University Seoul Hospital, 59 Daesagwan-ro, Yongsan-gu, Seoul 04401, Korea

Tel +82-2-709-9430

E-mail genuine43@schmc.ac.kr

Received: July 23, 2021

Revised: August 27, 2021

Accepted: September 10, 2021
This is an Open Access article distributed under the terms of the Creative Commons Attribution Non-Commercial License (http://creativecommons.org/licenses/ by-nc/4.0) which permits unrestricted non-commercial use, distribution, and reproduction in any medium, provided the original work is properly cited.
Background: Coronavirus disease 2019 (COVID-19) is a serious infectious disease caused by the highly contagious severe acute respiratory syndrome coronavirus 2 (SARS-CoV-2). In this study, three types of kits for the lateral flow assay (LFA) and two types of reagents used in the chemiluminescent immunoassay (CLIA) for serological testing of COVID-19 were evaluated and compared to investigate the current status of antibody testing.

Methods: From January 2020 to February 2021, 193 positive and 94 negative samples were tested. For these samples, WonMed COVID-19 immunoglobulin M (IgM)/immunoglobulin G (IgG) (Wonmed, Korea), careUS COVID-19 IgM/IgG (WELLS BIO, Korea), and STANDARD Q COVID-19 IgM/IgG Plus test (SD Biosensors, Korea) kits were used for the LFA, and Anti-SARS-CoV2 Elecsys nucleocapsid (N) and spike (S) (Roche, Switzerland) and ACCESS SARSCoV-2 IgM and IgG (Beckman Coulter, USA) for the CLIA were compared and evaluated.

Results: All kits and reagents except Elecsys showed variable sensitivities of $46.1 \%-72.0 \%$ for IgM, and $85.0 \%-88.1 \%$ for IgG. Elecsys showed a sensitivity of $86.0 \%$ for the $\mathrm{N}$ antibody and $85.5 \%$ for the $\mathrm{S}$ antibody. All reagents showed higher sensitivity in samples 14 days after symptom onset than within 14 days $(P=0.007)$. The specificity of LFA and CLIA was $97.9 \%-100.0 \%$. Conclusions: Most kits and reagents showed low clinical sensitivity at 7-14 days, that is before the antibody was sufficiently produced. When performing a serological test, IgM and IgG should be checked together to obtain sufficient clinical sensitivity, and the test timing should also be applied carefully.

(Lab Med Qual Assur 2021;43:199-207)

Key Words COVID-19, SARS-COV-2, COVID-19 serological testing, Immunoassay, Antibodies

\section{서론}

Coronavirus disease 2019 (COVID-19)는 2019년에 시작하 여 전 세계적으로 수천만 명 이상 빠른 전염이 되고 있는 severe acute respiratory syndrome coronavirus 2 (SARS-CoV-2) 에 의한 심각한 감염병이다. COVID- 19 는 $81 \%$ 의 환자가 폐렴이 없거나 경증 폐렴의 증상을 보이며, $1 \%$ 는 발열을 포함한 전형적 인 증상이 없는 무증상 환자이기에 지역사회 및 가정 내 2차 감염 
이 빠르게 진행되고 있다[1]. 심각한 호흡곤란, 패혈성 쇼크 등의 증상을 보이는 경우는 $5 \%$ 가량으로 알려져 있으며, 심각한 증상 을 보이는 환자의 사망률은 $62 \%$ 에 이르기도 한다[1,2]. 높은 전 파력과 사망률 때문에 COVID-19의 빠른 진단이 중요하며, 임상검 사실에서 바이러스 DNA 검출을 위해 우선되는 방식은 real-time reverse transcription polymerase chain reaction (RT-PCR) 이다[3]. SARS-CoV-2는 positive strand RNA를 가진 코로나바 이러스로 5' untranslated region (UTR), replicase complex (orf1ab, RdRp), $S$ gene, $E$ gene, $M$ gene, $N$ gene, 3' UTR 등 으로 구성되어 있다[4]. 이 중 국내에서는 orf1ab/RdRp gene과 E gene 또는 여기에 N gene을 추가한 RT-PCR이 주로 사용되며, 비인두 도말 검체에 대한 RT-PCR을 단독으로 진단에 사용할 경우 민감도는 $73.3 \%-93.0 \%$, 특이도는 $98.8 \%-100.0 \%$ 로 알려져 있 다[3,5,6].

감염 후 약 1 주가 지나면 바이러스에 대한 항체가 검출되 기 시작하며, RT-PCR이 음성이면서 감염이 의심되는 증상 을 보이는 환자에서 진단에 도움이 될 수 있다[7,8]. 항체검사 는 immunoglobulin M (IgM), immunoglobulin G (IgG), immunoglobulin A (IgA) 혹은 total antibody를 감지하는 검사 이다. 이는 분자검사에 보조적으로 사용하거나, 질병에 이환되지 않은 개인에서 이전의 감염 혹은 지역사회 노출을 확인하거나, 환 자에서 항체반응을 확인하기 위해 사용될 수 있다[8]. 이들은 PCR 결과가 음전된 이후에도 감염에 대한 면역반응을 관찰할 수 있어 장기적인 관찰에 유용하다. 항체검사를 위한 다양한 키트가 시장 에 공개되고 있으며, 민감도 및 특이도에 대한 평가가 이루어지고 있다. 이 중 임상검사실에서 널리 사용할 수 있는 항체검사는 주 로 lateral flow assays (LFAs) 키트를 통한 항체 검출이며, 검사 가 용이하고 빠르게 결과를 확인할 수 있는 것이 장점이다[9]. LFA 키트가 아닌, enzyme-linked immunosorbent assays (ELISA) 및 자동화장비를 사용한 chemiluminescent immunoassays (CLIA) 방식의 검사도 가능하며, 이 중 CLIA 기법이 ELISA 및 LFA 보다 더 민감한 것으로 알려져 있다[8]. 전 세계적으로 많은 국가 에서 백신 접종이 이루어지고 있어, 백신 접종 후 항체 형성 확인 에 사용할 수 있는 혈청학적 검사와 그 유용성도 관심이 높아지고 있다.

본 연구에서는 현장에서 바로 검사할 수 있는 LFA 키트 3종과 Roche, Beckman-Coulter에서 제공하는 CLIA 시약을 평가하여 COVID-19 혈청학적 검사의 현주소와 임상적 유용성을 확인하고 자 한다.

\section{재료 및 방법}

\section{1. 검체}

2020년 1월부터 2021년 2월까지 COVID-19 백신을 접종하 지 않은 만 19 세 이상의 성인, 비인두 도말 검체를 사용한 SARSCoV-2 RT-PCR 결과, 양성을 보여 COVID-19 확진된 환자 46명 의 검체 199 개 및 내원 환자 중 RT-PCR 검사에서 음성이며 임 상적 증상이 없는 환자 98 명의 혈청 검체 98 개를 대상으로 하 였다. RT-PCR은 PowerChek 2019-nCoV Real-time PCR kit (Kogenbiotech, Seoul, Korea)을 사용하여 $E$ gene 및 RdRp gene의 cycle threshold 값이 $\leq 35$ 인 경우를 SARS-CoV-2 양성, $>35$ 인 경우는 SARS-CoV-2 음성으로 판정하였다. 양성 환자 중 증상 발현 시점으로부터 검사 시점까지의 기간별로 0-7일을 그 룹 1, 8-14일을 그룹 2, 15-21일을 그룹 3, 22일 이상을 그룹 4로 나누며, 혈청 검체 채취는 serum separator tube $5 \mathrm{~mL}$ 용기를 사용하였다. LFA 검사 및 CLIA 검사를 RT-PCR 양성 검체 및 RT$\mathrm{PCR}$ 음성 검체를 대상으로 검사하였고, 검체량이 부족하거나 5 가 지 검사 중 하나라도 검사결과의 판독이 불가능한 총 10 건은 결과 에서 제외하여 최종적으로 양성 검체 193 개, 음성 검체 94 개에 대 한 검사를 완료하였다(Table 1). 음성 검체는 hepatitis B surface antibody, hepatitis $\mathrm{C}$ virus antibody (anti-HCV), human immunodeficiency virus (HIV) antigen, HIV antibody, antinuclear antibody (ANA), rheumatoid factor 양성 여부를 확인하여 교차반응이 발생하는지를 확인하였다. 또한 이 연구는 Institutional Review Board of Soonchunhyang University Hospital, Seoul, Korea (IRB file no., SCHUH-2020-11-020)의 승인을 받았다.

Table 1. Number of patients and samples collected in this study

\begin{tabular}{lcc}
\hline \multicolumn{1}{c}{ Variable } & Positive & Negative \\
\hline Patients & 46 & 98 \\
Collected samples & 199 & 98 \\
Inadequate samples $^{*}$ & 6 & 4 \\
Group $^{\dagger}$ & & \\
Group 1 & 38 & \\
Group 2 & 38 & \\
Group 3 & 25 & \\
Group 4 & 92 & \\
Total tested samples & 193 & 94 \\
\hline
\end{tabular}

${ }^{*}$ Samples with insufficient volume or unreadable results. ${ }^{\dagger}$ Groups with samples collected for symptom onset from 0 to 7 days (group 1); from 8 to 14 days (group 2); from 15 to 21 days (group 3); 21 days or more (group 4). 


\section{Lateral flow assay 및 chemiluminescent immunoassays 기법}

LFA 키트로 WonMed COVID-19 IgM/IgG (Wonmed, Bucheon, Korea), careUS COVID-19 IgM/IgG (WELLS BIO, Seoul, Korea), STANDARD Q COVID-19 IgM/IgG Plus test (SD Biosensors, Suwon, Korea)를 사용하였고, CLIA method 는 Anti-SARS-CoV2 Elecsys nucleocapsid (N) 및 spike (S) (Roche, Basel, Switzerland)를 cobas e 602 module (Roche, Basel, Switzerland)로 검사하였고, ACCESS SARS-CoV-2 IgM, IgG (Beckman Coulter, Brea, CA, USA) 시약을 UniCel DxI 800 (Beckman Coulter)로 검사하여 비교 및 평가하였다. LFA 키트는 공통적으로 15 분 후 결과를 판독하였다. CLIA 시약 중 Anti-SARS-CoV2 Elecsys는 S 항원과 N 항원에 대한 항체를 개 별적으로 검출할 수 있다. Anti-SARS-CoV2 Elecsys는 IgG와 $\operatorname{IgM}$ 을 구분하지 않고 각 시약에 포함되어 있는 재조합 항원 $\mathrm{S}$ 또 는 N에 대한 항체 전반을 측정한다. Elecsys N은 cutoff index 1.0 미만은 음성, 1.0 이상은 양성으로 판정하였고, Elecsys $\mathrm{S}$ 는 $0.80 \mathrm{U} / \mathrm{mL}$ 미만을 음성, $0.80 \mathrm{U} / \mathrm{mL}$ 이상을 양성으로 판정하고 $250 \mathrm{U} / \mathrm{mL}$ 까지를 검출범위로 지정하였다. ACCESS SARS-CoV-2 시약 중 IgM은 1.00 signal-to-cutoff ratio (S/CO) 미만을 nonreactive, $1.00 \mathrm{~S} / \mathrm{CO}$ 이상을 reactive로 정의하였으며, IgG에서 는 $0.80 \mathrm{~S} / \mathrm{CO}$ 이하를 non-reactive, 0.80 초과 $1.00 \mathrm{~S} / \mathrm{CO}$ 미만 을 equivocal, 그리고 $1.00 \mathrm{~S} / \mathrm{CO}$ 이상을 reactive로 정의하였다. 모든 과정은 제조사에서 제안하는 프로토콜에 따라 경험 있는 병 리사가 검사를 수행하였다. 제조사에서 제공한 각 키트 및 시약의
특성은 Table 2와 같다[10-16].

\section{3. 통계분석}

수집한 데이터를 IBM SPSS Statistics ver. 26.0 (IBM Corp., Armonk, NY, USA)로 분석하였다. 각 검사방법 및 그룹별 임상적 민감도의 차이를 확인하기 위해 비교대상의 수에 따라 KruskalWallis 검정 및 Mann-Whitney 검정을 사용하여 비교하였고, 키 트 및 시약별 일치도를 확인하기 위해 Cohen's kappa 및 Fleiss' kappa 분석을 사용하여 검사결과를 비교하였다. $P$ 값이 0.05 이 하일 때 분석이 통계적으로 유의하다고 판정하였다.

\section{결과}

RT-PCR 결과와 비교하여 전체 검사결과의 민감도, 특이도, 양 성 예측률, 음성 예측률을 조사하였다(Table 3). LFA 키트 3종은 $\operatorname{IgM}$ 에서 $46.1 \%-61.1 \%$ 의 민감도를 보였고 IgG에서는 $87.6 \%$ $88.1 \%$ 의 민감도를 보였다. CLIA 시약 중 ACCESS SARS-CoV-2 는 $\operatorname{IgM}$ 에서 $72.0 \%$ 의 민감도를 보였고 $\operatorname{IgG}$ 에서는 $85.0 \%$ 의 민감 도를 보였다. Elecsys 시약은 $\mathrm{N}$ 항체에서 $86.0 \%$ 의 민감도, $\mathrm{S}$ 항 체에서 $85.5 \%$ 의 민감도를 보였다. LFA 키트의 IgM에 대한 특이 도는 97.9\%-100.0\%였고 IgG에 대한 특이도는 94.7\%-97.9\%였 다. ACCESS 시약은 IgM에서 $100.0 \%$ 의 특이도, IgG에서 $98.9 \%$ 의 특이도를 보였다. Elecsys 시약의 특이도는 N 항체 $100.0 \%, \mathrm{~S}$ 항체 $100.0 \%$ 로 나타났다.

WonMed COVID-19 키트 및 careUS COVID-19 키트는 IgG에

Table 2. Manufacturer-provided clinical sensitivity/clinical and analytical specificity

\begin{tabular}{|c|c|c|c|c|}
\hline Kit & Antibody & Sample type & Capture antigen & Assay type \\
\hline \multirow[t]{2}{*}{ WonMed COVID-19 kit [10] } & $\lg M$ & Serum, plasma & S1 RBD domain & Gold conjugate LFA \\
\hline & $\lg G$ & Serum, plasma & $\mathrm{N}$ & Gold conjugate LFA \\
\hline \multirow[t]{2}{*}{ careUS COVID-19 IgM/IgG kit [11] } & $\lg M$ & Serum, plasma & $\mathrm{N}$ & Gold conjugate LFA \\
\hline & IgG & Serum, plasma & $\mathrm{N}$ & Gold conjugate LFA \\
\hline \multirow[t]{2}{*}{ STANDARD Q COVID-19 IgM/IgG Plus [12] } & $\lg M$ & Serum, plasma, whole blood & $\mathrm{N}, \mathrm{S}$ & Gold conjugate LFA \\
\hline & $\lg G$ & Serum, plasma, whole blood & $\mathrm{N}, \mathrm{S}$ & Gold conjugate LFA \\
\hline \multirow[t]{2}{*}{ ACCESS SARS-CoV-2 IgM/IgG $[13,14]$} & $\lg M$ & Serum, plasma & S1 RBD domain & CLIA \\
\hline & $\operatorname{IgG}$ & Serum, plasma & S1 RBD domain & CLIA \\
\hline \multirow[t]{2}{*}{ Anti-SARS-CoV2 Elecsys $[15,16]$} & Total & Serum, plasma & $\mathrm{N}$ & ECLIA \\
\hline & Total & Serum, plasma & S1 RBD domain & ECLIA \\
\hline
\end{tabular}

The instruments used were from the following companies: Wonmed (Bucheon, Korea); WELLS BIO (Seoul, Korea); SD Biosensors (Suwon, Korea); Beckman Coulter (Brea, CA, USA); and Roche (Basel, Switzerland).

Abbreviations: IgM, immunoglobulin M; S, spike; RBD, receptor binding domain; LFA, lateral flow assay; IgG, immunoglobulin G; N, nucleocapsid; CLIA, chemiluminescent immunoassay; ECLIA, electrochemiluminescence immunoassay. 


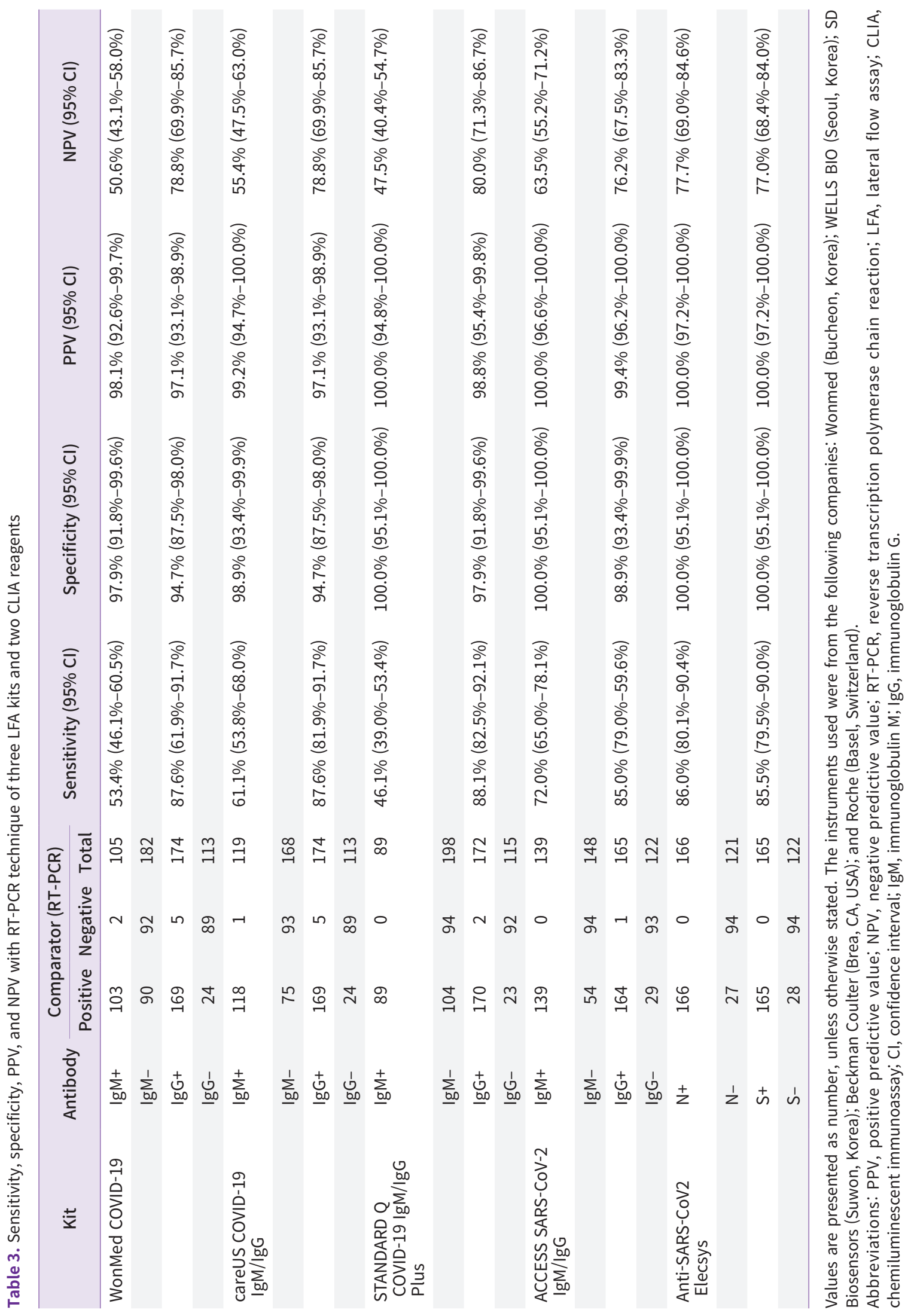




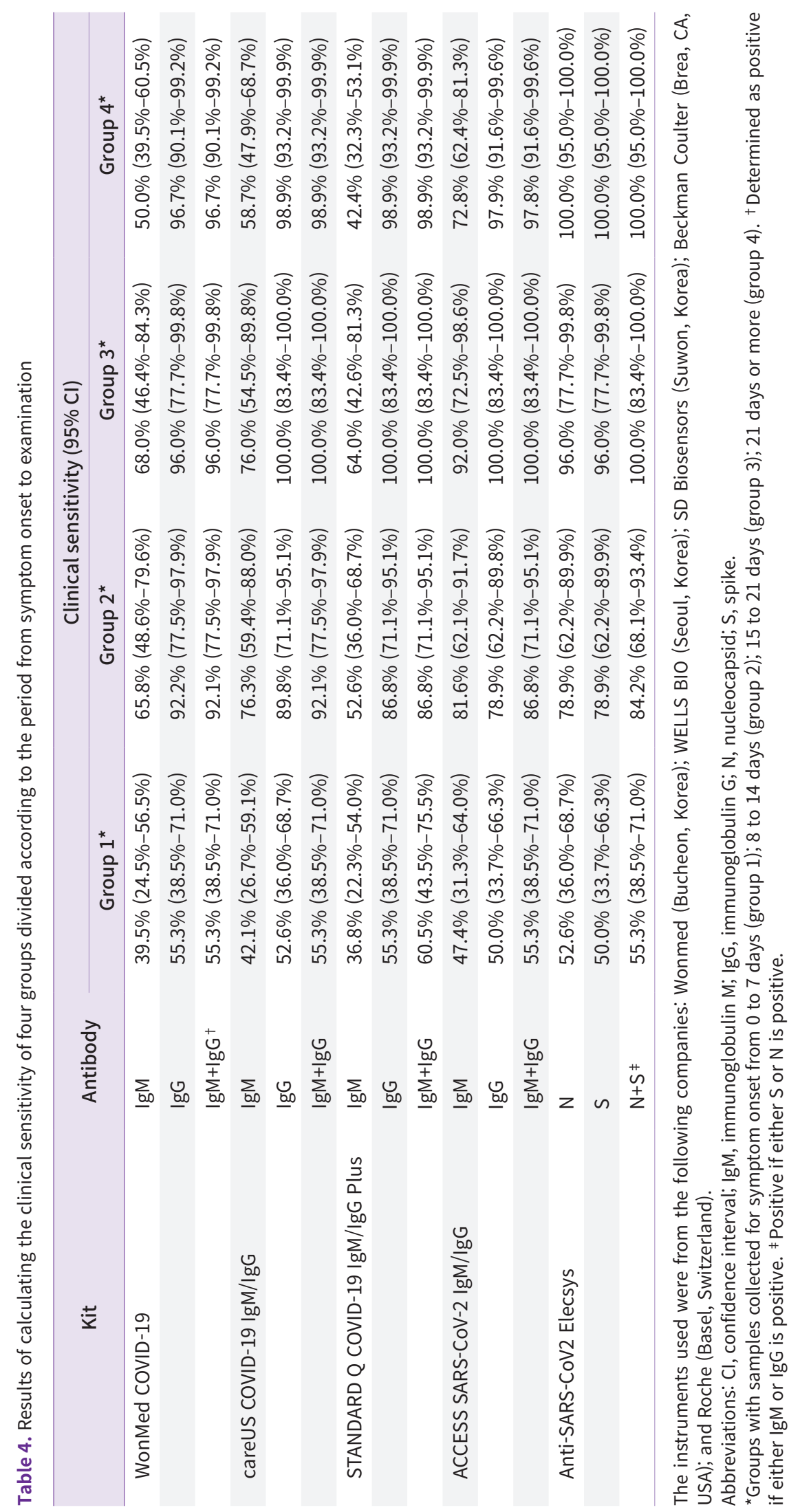


서 각각 5\% (5/94), 5\% (5/94)의 위양성을 보였고 STANDARD Q CoVID-19 키트는 2\% (2/94)의 위양성을 보였다. IgM에서 는 WonMed 키트가 2\% (2/94), careUS 키트가 $1 \%$ ( $1 / 94)$, STANDARD Q 키트는 위양성을 보이지 않았다. CLIA 시약 중에 서는 ACCESS SARS-CoV-2 시약이 IgG에서 1\% (1/94) 위양성을 보였고 Elecsys 시약은 위양성을 보인 검체가 없었다.

양성 환자를 증상 발현 후 검사 일시까지의 기간별로 4 개의 그 룹으로 나누어 보았을 때(Table 4), 대부분의 키트 및 시약이 항체 가 충분히 생성되기 전의 기간인 7-14일 전에서 임상적 민감도가 낮게 나타났다. 그룹 1 과 그룹 2 사이에는 임상적 민감도의 차이 가 있었고 $(P=0.008)$, 그룹 2 와 그룹 3 간에는 차이가 뚜렷하지 않 았으며 $(P=0.292)$ 그룹 3 과 그룹 4 간에도 차이가 관찰되지 않았 다 $(P=0.317)$. 그룹 1 에서 2 , 그룹 3 에서 4 의 두 그룹을 비교했을 때는 임상적 민감도에 뚜렷한 차이가 있어( $P=0.007)$ LFA 및 CLIA 기법 모두 그룹3 이후의 검체에서 민감도가 높게 나타났다.

Elecsys 시약은 그룹 3 , 그룹 4의 검체에서 N, S 항체 검사 모두
$96.0 \%, 100 \%$ 의 민감도를 보여 항원의 종류-N, S 여부에 관계 없 이 항체 형성은 2 주가 지나면 검출에 충분할 정도로 형성되는 것 으로 보인다. Elecsys 검사는 $\operatorname{lgM}, \operatorname{lgg}$ 를 구분할 수 없기 때문에 항체의 subtype에 따른 차이는 확인할 수 없었다.

ACCESS SARS-CoV-2 에 대한 본 연구의 데이터에서는 전체 검체를 대상으로 했을 때 $\operatorname{lgM}$ 의 민감도 $71.9 \%, \operatorname{lgG}$ 의 민감도 $83.9 \%$ 를 보였으며 역시 그룹 1 에서는 각각 $47.5 \%, 47.5 \%$ 로 낮 은 민감도를 보였다. 14 일 이후의 검체를 대상으로 했을 때는 $\operatorname{lgM}$ $77.5 \%$, IgG $98.3 \%$ 의 민감도로, $\operatorname{lgG}$ 가 $\operatorname{lgM}$ 보다 더 민감하였다. 환자에 따라 IgM의 형성 정도에는 차이가 있었다.

증상 발현 후 2 주 이전의 그룹 1 과 그룹 2 사이에서 $\operatorname{lgM}(P=$ $0.009)$ 은 먼저 통계적으로 유의한 차이를 보였고, $\operatorname{lgG}(P=0.233)$ 는 통계적으로 유의한 차이가 보이지 않았다. 그룹 2와 그룹 3 간 에 IgM은 뚜렷한 증가를 확인할 수 없었으며( $P=0.279), \operatorname{IgG}$ 는 그 룹 2 와 3 사이를 기준으로 항체 검출이 증가했다 $(P<0.001)$.

각 키트 및 시약별 결과의 일치도를 조사한 결과, $\operatorname{lgM}$ 에서

Table 5. Cohen's kappa (95\% confidence interval) concordance between each kit and reagent

\begin{tabular}{|c|c|c|c|c|c|}
\hline & WonMed & careUS & STANDARD Q & ACCESS & Elecsys \\
\hline \multicolumn{6}{|l|}{$\lg M$} \\
\hline WonMed & - & & & & \\
\hline careUS & $0.766(0.691-0.842)$ & - & & & \\
\hline STANDARD Q & $0.674(0.584-0.764)$ & $0.687(0.602-0.772)$ & - & & \\
\hline ACCESS & $0.621(0.532-0.709)$ & $0.790(0.716-0.860)$ & $0.619(0.534-0.705)$ & - & \\
\hline RT-PCR & $0.413(0.331-0.495)$ & $0.500(0.516-0.584)$ & $0.359(0.284-0.435)$ & $0.628(0.545-0.711)$ & \\
\hline \multicolumn{6}{|l|}{ IgG } \\
\hline WonMed & - & & & & \\
\hline careUS & $0.898(0.846-0.950)$ & - & & & \\
\hline STANDARD Q & $0.913(0.864-0.961)$ & $0.942(0.902-0.982)$ & - & & \\
\hline ACCESS & $0.892(0.839-0.945)$ & $0.878(0.821-0.934)$ & $0.892(0.839-0.945)$ & - & \\
\hline RT-PCR & $0.782(0.708-0.856)$ & $0.782(0.708-0.856)$ & $0.813(0.744-0.882)$ & $0.780(0.706-0.853)$ & \\
\hline \multicolumn{6}{|l|}{ Total $^{*}$} \\
\hline WonMed & - & & & & \\
\hline careUS & $0.897(0.845-0.950)$ & - & & & \\
\hline STANDARD Q & $0.927(0.883-0.971)$ & $0.927(0.882-0.971)$ & - & & \\
\hline ACCESS & $0.898(0.847-0.950)$ & $0.883(0.828-0.939)$ & $0.913(0.865-0.961)$ & - & \\
\hline Elecsys $^{+}$ & $0.869(0.821-0.918)$ & $0.898(0.855-0.941)$ & $0.928(0.883-0.972)$ & $0.942(0.903-0.982)$ & - \\
\hline RT-PCR & $0.782(0.708-0.856)$ & $0.795(0.734-0.855)$ & $0.827(0.771-0.883)$ & $0.814(0.745-0.883)$ & $0.829(0.763-0.895)$ \\
\hline
\end{tabular}

The instruments used were from the following companies: Wonmed (Bucheon, Korea); WELLS BIO (Seoul, Korea); SD Biosensors (Suwon, Korea); Beckman Coulter (Brea, CA, USA); and Roche (Basel, Switzerland).

Abbreviations: IgM, immunoglobulin M; IgG, immunoglobulin G; RT-PCR, reverse transcription polymerase chain reaction.

${ }^{\star}$ Determined as positive if either IgM or IgG was positive. ${ }^{\dagger}$ Positive if either spike or nucleocapsid was positive. 
0.619-0.790의 일치도를 보였고 대부분 중등도에서 좋은 일치 도를 보였고(Table 5), RT-PCR과는 다소 낮은 일치도를 보였다 (0.359-0.628). IgG에서는 0.878-0.942의 좋은 일치도를 보였고 RT-PCR과는 0.780-0.813의 일치도였다. IgM 혹은 $\operatorname{lgG}$ 둘 중 하 나에서만 양성이 나온 경우를 전체 양성으로 판정하였을 때, 역시 0.883-0.927로 좋은 일치도를 보였으며, Elecsys에서 N 혹은 S 항원 양성을 전체 양성으로 판정했을 경우와도 아주 좋은 일치도 (0.829-0.942)를 보였다. RT-PCR과 전체 양성의 일치도 또한 좋 음에서 아주 좋음의 일치도(0.782-0.829)를 보였다.

\section{고찰}

지금까지 보고된 바에 의하면 IgG는 증상 발현 후 12-15일, IgM은 4-14일, IgA는 4-24일 가량이 검출되기 시작하는 평균 혹 은 중앙값이다[17]. 항체가 검출되는 기간에 대해서는 다양한 보 고가 있으나 $\operatorname{lgM}$ 의 경우 정점까지 증가했다가 증상 발현 후 3-5 주부터 감소하기 시작하며, $\operatorname{lgG}$ 의 경우 증상 발현 후 50 일 전후로 정점까지 증가한 이후 비교적 평탄하게 감소하며 7개월 이후까지 도 검출이 보고되어 있다[18-20].

LFA 키트에 대한 타 연구의 민감도는 52.8\%-94.6\%로 보고되 어 본 연구와 유사했다[7,21,22]. $\operatorname{lgM}$ 또는 $\operatorname{lgG}$ 둘 중 하나만 양 성이어도 양성으로 판정했을 때 증상 발현 후 15 일 이후의 결과 는 $88.0 \%$ 까지 상승하는 소견을 공통적으로 보였고[23], 타 연 구에서도 $\operatorname{lgM}$ 을 단독으로 보았을 때 민감도가 $32.5 \%-76.1 \%$, $\operatorname{IgG}$ 를 단독으로 보았을 때 53.7\%-85.9\%로 보고되어 있어 본 연구의 민감도와 유사했다[21,24]. CLIA 방식의 검사 민감도는 $79.9 \%-94.4 \%$, 그 중에서 Anti-SARS-CoV2 Elecsys의 민감도는 $94.95 \%$ 로 본 연구의 2주 이상 검체를 대상으로 했을 때의 결과와 유사하다[7,21]. 평가한 키트와 시약의 종류에는 다소 차이가 있 으나, 전체적인 임상적 유용도는 유사할 것으로 생각된다.

위양성 중 교차반응으로 의심되는 결과가 WonMed kit 및 ACCESS SARS-CoV-2 IgG 시약에서 1건 확인되었다. 해당 환 자는 ANA에서 nuclear membranous pattern으로 강양 성(>1:5,120)을 보였으며, 추출핵항원(extractable nuclear antigen, ENA)에서 U1-nuclear ribonucleoprotein (nRNP), anti-Ro, anti-double-stranded DNA (dsDNA), anticentromere protein $\mathrm{B}$ 에서 양성을 보였다. 그러나 ANA 정량에 서 1:2,560 이상의 강양성을 보인 다른 환자 3 인에서는 교차반응 이 보이지 않았으며, 교차반응이 확인된 검체에서만 양성을 보인 ENA 결과는 U1-nRNP, anti-dsDNA였다. U1-nRNP 항체는 U1 ribonucleoprotein (RNP)에 대한 항체로, 바이러스 또한 RNP 로 구성되어 있으므로 이에 대한 높은 항체가 혈청학적 검사에
서 검출된 것으로 생각된다. dsDNA 항체 또한 바이러스 구성 성 분인 핵산에 대한 항체로 교차반응을 일으킨 것으로 보인다. 그 러나 과거 감염의 가능성 또한 배제할 수 없다. ACCESS SARSCoV-2 IgG 시약과 Elecsys S 시약 모두 바이러스의 S1 항원 중 receptor binding domain에 대한 항체를 검출하는 시약이므로 교차반응의 차이는 추가적인 확인이 필요하다. 그 외 hepatitis A virus antibody, anti-HCV, HIV antigen, HIV antibody와는 교 차반응을 관찰할 수 없었다.

또한 LFA의 위양성 검체 중 2 건은 특이 병력 없는 환자의 검 체로 세 종류의 LFA 키트 모두에서 IgM 음성, IgG 양성을 보였 고, CLIA 시약을 사용한 검사에서는 모두 음성을 보였다. 다만, ACCESS SARS-CoV-2 IgG에서 0.96, 0.79로 optical density 값 이 cutoff 미만이긴 하였으나 다른 음성 환자보다 다소 높은 양상 을 보였고 Elecsys 시약에서는 $\mathrm{S}$ 는 두 건 모두 0.4 미만, N은 각각 $0.132,0.080$ 으로 음성을 보였다. 상기한 결과는 과거 COVID-19 감염으로 인해 생성된 항체에 의한 LFA 진양성일 가능성도 있으 나, CLIA 법에서는 둘 모두 음성을 보여 가능성은 다소 떨어지며, SARS-CoV-2 외의 코로나 바이러스 감염에서도 IgG ELISA 양성 을 보인 보고도 있어 주의가 필요하다[25,26].

WonMed COVID-19 키트의 재검률이 20\%로 다른 키트에 비 해 높았다. 재검률이 높은 사유 중 하나는 버퍼의 이동거리가 다 른 키트에 비해 길어 control line까지 온전히 검체가 도달하기 전 에 건조되어 버린다는 점이다. 일부 버퍼가 전혀 이동하지 않는 불 량도 수 건 확인되었다. 적정량의 버퍼 사용과 검사자의 숙련도가 검사 성공률을 다소 상승시킬 수 있을 것으로 생각되나, 빠른 건조 문제는 해결하지 못했다. 검체 접종위치와 버퍼 접종위치가 다른 점이 많은 검체를 검사할 때 오염률을 줄이는 것에 도움이 될 것이 나, 버퍼의 이동거리를 늘린다는 한계가 있었다. WonMed 키트 가 재검률이 높았으나, LFA 키트 전체의 일치도는 IgM의 kappa 계수 0.620 (95\% confidence interval [Cl], 0.618-0.623; $P<0.001), \operatorname{lgG}$ 의 kappa 계수 $0.830(95 \% \mathrm{Cl}, 0.827-0.832$; $P<0.001)$ 로 높은 일치도를 보였으며, 민감도와 특이도 또한 다른 키트와 유사하여 성능적으로 큰 차이는 없을 것이다.

각 키트 및 시약의 일치도는 $\operatorname{lgM}$ 에서 다소 낮고 $\operatorname{lgG}$ 에서 좋은 일치도를 보였고 WonMed 키트도 유사한 일치도였다. 그러나 $\operatorname{lgM}$ 혹은 $\operatorname{lgG}$ 단일로 판정하기보다 IgM+lgG 양성의 kappa 계수 가 뚜렷하게 좋은 일치도로 나타나 임상적으로는 $\operatorname{lgM}+\operatorname{lgG}$ 양성을 참고해야 할 것이다. Elecsys 시약의 경우 비교대상 중 유일하게 $\operatorname{IgM}, \operatorname{IgG}$ 를 구분할 수 없으나 N+S 양성을 비교했을 때 모두 아주 좋은 일치도를 보여 임상적 사용에 유용할 것으로 보인다.

본 연구에서는 LFA 키트 3종과 CLIA 시약 2종을 비교하여 분석 한 정보를 제공한다. LFA 키트는 특별한 장비가 없어도 어디서든 
사용이 가능하지만, CLIA 시약은 적절한 설비가 필요하다. 혈청학 적 유병률, 감염 후 혈청학적 반응 확인 등을 위해 검사방법을 선 택할 때 필요한 성능 비교평가의 제시가 본 연구의 목적이다.

모든 키트 및 시약은 증상 발현 후 14 일 이후의 검사에서 충분 한 민감도를 보이며 특히 7 일 전인 그룹 1 의 민감도는 $55.3 \%-$ $60.5 \%$ 에 불과해 해당 시기의 환자에서는 혈청학적 검사 외의 RT$\mathrm{PCR}$ 과 같은 검사를 통해 환자의 상태를 확인하는 것이 적절할 것 이다. 특이도는 모든 검체에 대해 모든 검사가 높은 특이도를 보였 으나, 일부 위양성을 보여 이에 대한 주의가 필요하다. 이와 같이 혈청학적 검사를 할 때 $\operatorname{lgM}$ 과 $\operatorname{lgG}$ 를 함께 확인해야 충분한 임상적 민감도를 얻을 수 있을 것이며, 검사 시점 또한 주의하여 적용하여 야 할 것이다.

\section{감사의 글}

이 논문은 대한임상검사정도관리협회의 2021년 학술연구비 지
원을 받아 시행한 결과를 바탕으로 작성되었다(과제번호: 2021005).

\section{ORCID}

Wooyong Shin https://orcid.org/0000-0001-5588-6919 Hae In Bang https://orcid.org/0000-0001-7854-3011 Geun Young Yu Mi-Young Kim https://orcid.org/0000-0002-0089-031X https://orcid.org/0000-0002-8359-2392 Eui Young Jang Jung-Ah Kim Jieun Kim Rojin Park Jeong Won Shin https://orcid.org/0000-0001-5411-6293 https://orcid.org/0000-0003-1295-4728 https://orcid.org/0000-0002-7794-3475 https://orcid.org/0000-0003-2866-037X https://orcid.org/0000-0001-6913-4793 Tae Youn Choi https://orcid.org/0000-0002-1950-8010

\section{REFERENCES}

1. Wu Z, McGoogan JM. Characteristics of and important lessons from the coronavirus disease 2019 (COVID-19) outbreak in China: summary of a report of 72314 cases from the Chinese Center for Disease Control and Prevention. JAMA 2020;323:1239-42.

2. Weiss P, Murdoch DR. Clinical course and mortality risk of severe COVID-19. Lancet 2020;395:1014-5.

3. Cheng MP, Papenburg J, Desjardins M, Kanjilal S, Quach C, Libman M, et al. Diagnostic testing for severe acute respiratory syndrome-related coronavirus 2: a narrative review. Ann Intern Med 2020;172:726-34.

4. Zhu N, Zhang D, Wang W, Li X, Yang B, Song J, et al. A novel coronavirus from patients with pneumonia in China, 2019. N Engl J Med 2020;382:727-33.

5. Boger B, Fachi MM, Vilhena RO, Cobre AF, Tonin FS, Pontarolo R. Systematic review with meta-analysis of the accuracy of diagnostic tests for COVID-19. Am J Infect Control 2021;49:21-9.

6. Kandel C, Zheng J, McCready J, Serbanescu MA, Racher H, Desaulnier M, et al. Detection of SARS-CoV-2 from saliva as compared to nasopharyngeal swabs in outpatients. Viruses 2020;12:1314.

7. Weidner L, Gansdorfer S, Unterweger S, Weseslindtner L, Drexler C, Farcet M, et al. Quantification of SARS-CoV-2 antibodies with eight commercially available immunoassays. J Clin Virol 2020;129:104540.

8. Bohn MK, Loh TP, Wang CB, Mueller R, Koch D, Sethi S, et al. IFCC interim guidelines on serological testing of antibodies against SARS-CoV-2. Clin Chem Lab Med 2020;58:2001-8.

9. Premraj A, Aleyas AG, Nautiyal B, Rasool TJ. Nucleic acid and immunological diagnostics for SARS-CoV-2: processes, platforms and pitfalls. Diagnostics (Basel) 2020;10:866.

10. Wonmed. WonMed Covid-19 IgG/IgM. http://www.wonmed.com/page/product01_03_02 (Accessed March 19, 2021).

11. WELLS BIO. CareUS COVID-19 IgM/IgG. http://www.wellsbio.net/eng/goods/view.asp?idx=79\&category=5\&search_ type=0\&search_word=\&page_size=8\&page=1 (Accessed March 19, 2021).

12. SD Biosensor. STANDARD Q COVID-19 IgM/IgG Plus test. https://www.sdbiosensor.com/product/product_ view?product_no=239 (Accessed March 19, 2021). 
13. Beckman Coulter. ACCESS SARS-CoV-2 IgM Antibody Test. https://www.beckmancoulter.com/products/ immunoassay/access-sars-cov-2-igm-antibody-test (Accessed March 19, 2021).

14. Beckman Coulter. ACCESS SARS-CoV-2 IgG Antibody Test. https://www.beckmancoulter.com/products/ immunoassay/access-sars-cov-2-igg-antibody-test (Accessed March 19, 2021).

15. Roche Diagnostics. Elecsys Anti-SARS-CoV-2. https://diagnostics.roche.com/global/en/products/params/elecsys-antisars-cov-2.html (Accessed March 19, 2021).

16. Roche Diagnostics. Elecsys Anti-SARS-CoV-2 S. https://diagnostics.roche.com/global/en/products/params/elecsysanti-sars-cov-2-s.html (Accessed March 19, 2021).

17. Post N, Eddy D, Huntley C, van Schalkwyk M, Shrotri M, Leeman D, et al. Antibody response to SARS-CoV-2 infection in humans: a systematic review. PLoS One 2020;15:e0244126.

18. Fung M, Chiu CY, DeVoe C, Doernberg SB, Schwartz BS, Langelier C, et al. Clinical outcomes and serologic response in solid organ transplant recipients with COVID-19: a case series from the United States. Am J Transplant 2020;20:322533.

19. Lee YL, Liao CH, Liu PY, Cheng CY, Chung MY, Liu CE, et al. Dynamics of anti-SARS-Cov-2 IgM and IgG antibodies among COVID-19 patients. J Infect 2020;81:e55-8.

20. Ortega N, Ribes M, Vidal M, Rubio R, Aguilar R, Williams S, et al. Seven-month kinetics of SARS-CoV-2 antibodies and role of pre-existing antibodies to human coronaviruses. Nat Commun 2021;12:4740.

21. Kontou PI, Braliou GG, Dimou NL, Nikolopoulos G, Bagos PG. Antibody tests in detecting SARS-CoV-2 infection: a meta-analysis. Diagnostics (Basel) 2020;10:319.

22. Trombetta BA, Kandigian SE, Kitchen RR, Grauwet K, Webb PK, Miller GA, et al. Evaluation of serological lateral flow assays for severe acute respiratory syndrome coronavirus-2. BMC Infect Dis 2021;21:580.

23. Perez-Garcia F, Perez-Tanoira R, Romanyk J, Arroyo T, Gomez-Herruz P, Cuadros-Gonzalez J. Alltest rapid lateral flow immunoassays is reliable in diagnosing SARS-CoV-2 infection from 14 days after symptom onset: a prospective single-center study. J Clin Virol 2020;129:104473.

24. Serrano MM, Rodriguez DN, Palop NT, Arenas RO, Cordoba MM, Mochon M, et al. Comparison of commercial lateral flow immunoassays and ELISA for SARS-CoV-2 antibody detection. J Clin Virol 2020;129:104529.

25. Chaudhury S, Hutter J, Bolton JS, Hakre S, Mose E, Wooten A, et al. Serological profiles of pan-coronavirus-specific responses in COVID-19 patients using a multiplexed electro-chemiluminescence-based testing platform. PLoS One 2021;16:e0252628.

26. Ng KW, Faulkner N, Cornish GH, Rosa A, Harvey R, Hussain S, et al. Preexisting and de novo humoral immunity to SARS-CoV-2 in humans. Science 2020;370:1339-43. 